\title{
Oneomedicine
}

2019; 4: 1-9. doi: $10.7150 /$ oncm. 28210

Review

\section{Telomere and Its Role in Diseases}

\author{
Stephanie Wang1, Chikezie O. Madu², Yi Lu ${ }^{3}$ \\ 1. Departments of Biology and Advanced Placement Biology, White Station High School, Memphis, Tennessee 38117. USA. \\ 2. Departments of Biology and Advanced Placement Biology, White Station High School, Memphis, Tennessee 38117. USA. \\ 3. Department of Pathology and Laboratory Medicine, University of Tennessee Health Science Center, Memphis, TN 38163. USA. \\ $\square$ Corresponding author: Yi Lu, Ph.D., Department of Pathology and Laboratory Medicine, University of Tennessee Health Science Center, Cancer Research \\ Building, 19 South Manassas Street, Memphis, TN 38163 (USA), Tel.: (901) 448-5436, Fax.: (901) 448-5496, E-mail: ylu@uthsc.edu \\ (c) Ivyspring International Publisher. This is an open access article distributed under the terms of the Creative Commons Attribution (CC BY-NC) license \\ (https://creativecommons.org/licenses/by-nc/4.0/). See http://ivyspring.com/terms for full terms and conditions.
}

Received: 2018.06.29; Accepted: 2018.10.26; Published: 2019.01.23

\begin{abstract}
Telomeres are highly conservative repeated nucleotide sequences at the ends of linear chromosomes. Allowing effective DNA replication to keep the integrity of gene structure and the stability of chromosomes, telomeres protect the ends of the chromosome from deterioration or from fusion with neighboring chromosomes. Reduction in the telomere length leads to the cessation of cell division and thus cellular senescence. On the other hand, telomerase is a ribonucleoprotein complex with reverse transcriptase activity, protecting the telomere from being shortened. Thus, it is inactivated by synthesis and adds the repeated sequences onto the telomeres. Telomerase plays an important role in cell senescence and tumor formation.

Telomere length and telomerase activity may be mediated by immune, endocrine, and metabolic pathways and accelerate cellular dysfunction, ageing, and even induce cancer over one's lifespan. Significant attainment of telomerase to maintain telomere length could stop the cell senescence and aging related disease and also is required for the evolution of malignancy. This review discusses the role of telomeres and telomerase in humans during senescence and cancer. The evidence indicates that telomerase-induced telomere length manipulations could be targeted for anti-aging and anti-cancer therapy in the future.
\end{abstract}

Key words: Telomere, anti-aging, anti-cancer therapy

\section{Introduction}

The relationship between aging and cancer is one of the most important subjects in human studies. Both are caused by cellular damage and regulated by the cellular damage stress regulation gene.

Aging is an inevitable time-dependent degenerative disease in human beings that causes irreversible accumulation of disadvantageous mutations, cell division inability, increasing disease sensitivity, and eventually death. [1] Although various models and model organisms have been employed to investigate the mechanism of aging, the cause of aging is still uncertain. In 1961, Hayflick found that there is a "limit" for the number of normal human cell divisions, "Hayflick limit." This phenomenon of the limitation of cell division potential was called reproductive aging. His study proved that telomere shortening in humans eventually makes cell division impossible. This is the first-time people correlated telomere shortening with cell aging. [2] In 1998, Dr Bodnar [3] and Vazirimore [4] successfully exceeded the life-span of telomerase-negative normal human cell types through transfection with vectors encoding the human telomerase catalytic subunit. On the other side, the deficiencies in telomerase shorten telomeres and curtail the lifespan of mice. [5-7] It is well known that telomeres progressively shorten with increased aging and provide the biological clock mechanism for gene regulation over long periods of time without initializing a DNA damage signaling response. Since research has been found supporting that potentially harmful environmental factors or diseases are associated with short telomeres in humans, comparatively short telomere length has become the standard of poor health regardless of the person's age.

In contrast, dysfunctional telomeres can suppress cancer development by engaging replicative senescence or apoptotic pathways, but they can also 
promote tumor initiation. Telomerase protects telomeres from being shortened by adding repeated sequences. The telomerase level is low to undetectable in most somatic cells, which causes normal somatic cells to enter replicative senescence and undergo growth arrest or apoptosis; however, telomerase activity increases in about $85 \%$ of tumor cells. This overexpression of telomerase confers limitless replicative potential to tumor cells by abnormal continuous elongation of telomeres. [8] In 1994, Dr. Kim found that telomerase is activated in human malignant tissues but not in adjacent normal tissues. [9] The selective expression of telomerase in cancer cells provides evidence that telomerase activity could be used as a tumor indicator for effective diagnosis. Recently, valuable research from various laboratories has provided major insights into telomerase and telomeres, leading to their use as diagnostic and prognostic indicators in several types of cancer. [10] Considering the important role of telomerase in the maintenance of tumor cell growth, targeting telomeres throughout telomerase inhibition has been demonstrated to be an effective therapeutic strategy for cancers. [11, 12]

This review is an attempt to systematically analyze the role of telomeres and telomerase in regulating cell aging and cancer and the prospects for their use in anti-aging and anti-cancer.

\section{Structure and Function of Telomeres}

In humans, telomeres are composed of highly conservative repetitive nucleotide sequences and associated proteins. The telomeric DNA sequence is comprised of repeats, TTAGGGn, located at the end of linear chromosomes. [13] Telomeres stabilize chromosomes, preventing the fusion of their ends and also protecting the $3^{\prime}$ end of the chromosome against exonucleases. [14, 15]

Telomeres normally terminate with $3^{\prime}$ single-stranded G-rich DNA overhang that extends beyond double-stranded DNA region, which is essential for telomere maintenance and capping. [16, 17] This 3 ' end dangling chain folds back to telomere's double stranded region and pairs with the complementary strand to form a compact loop structure known as telomere loops, or T-loop. This triple-stranded structure is called a displacement loop or D-loop. Thus, the entire telomeric DNA sequence forms a lariat structure (D-T loop). [18] The T-loop at the end of chromosomes prevents the telomere ends from degrading or forming chromosomal fusion.

In human, shelterin is a significant protein complex that comprises six subunits and forms a cap structure, T-loop, at the end of chromosomes.
Shelterin consists of two double stranded DNA binding proteins (TRF1 and TRF2), one TIN2 protein (linking TRF1 and TRF2), one single stranded DNA binding protein POT1, one ligate single double-stranded protein TPP1, and 1 core protein. Shelterin plays an important role in protecting chromosomal ends from all aspects of the DNA damage response and regulating telomere maintenance by telomerase. [19] (Figure 1)

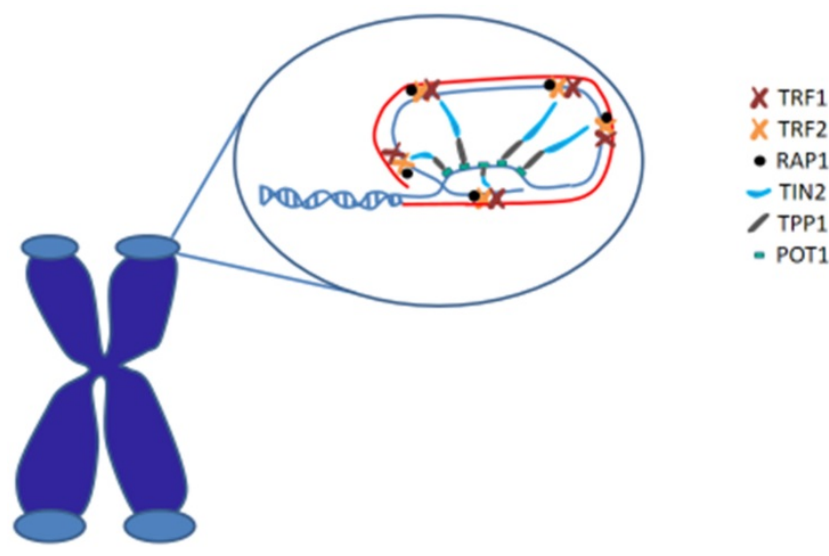

Figure 1. Telomeres are special nucleoprotein structures that cap the termini of chromosomes. The end of the telomere inserts back into the main body of the telomere to form the T-loop (red) and D-loop (blue). Telomeric DNA is coated by shelterin proteins that regulate chromosomal end protection.

\section{Structure and Function of Telomerase}

As the biological clock of cells, progressive telomere shortening has an extremely important effect on cellular senescence and cancer. In human stem cells, telomeres are maintained by a special ribonucleoprotein enzyme, called telomerase, which compensates the loss of telomeric sequences by adding telomeres at the $3^{\prime}$ end of the telomeric overhang. Telomerase consists of a reverse transcriptase enzyme (TERT), an RNA template (TERC), and stabilizing proteins including dyskerin (encoded by DKC1 and TCAB1). [20, 21] Human telomerase RNA template is a single copy gene, composed of around 455 nucleotides. In the absence of a DNA template, telomerase extends telomeric oligonucleotide ends with its own RNA template and compensates for the missing telomere ends during cell division. [22]

The telomerase ribonucleoprotein complex actively maintains telomere length and resists telomere shortening. [23-26] In normal conditions, high-grade telomerase expression usually occurs in the early stages of stem cell and embryonic development. However, there is almost undetectable telomerase activity in normal human somatic cells. Therefore, human physiological aging is accompanied 
by the lowering telomerase activity and shortening of telomeres. This is also thought to be the basis of aging and age-related diseases and the life span of the body. [27] Telomerase overexpression can extend the replication cycle of primary cells indefinitely, even causing them to become cancer cells. [28]

\section{Telomere Related Diseases and Therapies}

Telomere shortening is the primary molecular cause of aging and the age-related diseases. Telomere shortening induces chromosomal instability triggering the different telomere-targeted diseases, including tumors. A summary of telomere-related diseases, molecular mechanisms of telomeres, and recent advancement in the clinical development are described in Table 1.

\section{Immune Disease}

One of the main characteristics of the immune system is the constant renewal of its cells. At the same time, this renewal is highly dependent on the efficiency of telomere maintenance. Unlike somatic cells, lymphocytes have a robust capability to proliferate given their clonal expansion and have telomerase overexpression. The telomerase overexpression prevents significant telomere shortening during each division. Immunosenescence, referring to the immune function deregulation, makes elderly individuals prone to not only infectious diseases but also to malignancy and autoimmunity. CD28 is one of the molecules expressed in T cells that provide costimulatory signals that are required for T-cell activation, T-cell proliferation, cytokine production, and T-cell survival promotion. In elderly individuals with chronic viral infections and autoimmune diseases (e.g., multiple sclerosis (MS), rheumatoid arthritis (RA), and Wegener's disease, an increase in the frequency of CD28- $\mathrm{T}$ cells has been detected. [29, 30] Loss of CD28 expression is characterized by telomere shortening and reduced proliferative ability. The presence of CD28- $\mathrm{T}$ cells in both elderly individuals and patients with autoimmune diseases (ADs) has supported the concept that ADs are closely related to the cell aging process.

\section{Coronary Heart Disease}

Due to close relationship between telomere length and coronary heart disease, genome-wide association studies have mapped leukocyte telomere length-associated single-nucleotide polymorphisms (SNPs) to genetic loci. Genetic risk scores (GRSs) based on these SNPs were developed to predict susceptibility to cardiovascular disease and major cancers. When the GRS predicts short leukocyte telomere length, the probability of developing cardiovascular disease is increased. [31] Codd et al. conducted a genetic risk assessment of telomerase mutation in 22,233 coronary heart disease patients and 64,762 controls. [32] The results proved an association of shorter leukocyte telomere length with increased risk of coronary artery disease. Their finding supports a causal role of telomere-length variation in some age-related diseases.

\section{Hyperlipidemia}

Hyperlipidemia is an early and main cause of coronary heart disease. Studies found that hypercholesterolemia caused a significant reduction in phenotypically defined long-term hematopoietic stem cell compartment, telomere length, and repopulation capacity of c-kit+ Thy-1.1lo lineage-/lo Sca-1+ (KTLS) cells, indicating accelerated aging in these cells. These effects were p38-dependent and reversed in vivo by treatment of hypercholesterolemic mice with antioxidant $\mathrm{N}$-acetylcysteine. These results proved that hypercholesterolemia is also related to short telomere length. [33]

Table 1. Telomere Related Diseases and the Role of Telomeres

\begin{tabular}{|c|c|c|}
\hline Disease & Role of telomeres & Medical advancement \\
\hline $\begin{array}{l}\text { Chronic viral infections and autoimmune } \\
\text { diseases (e.g. multiple sclerosis (MS), } \\
\text { rheumatoid arthritis (RA), and Wegener's } \\
\text { disease) }\end{array}$ & $\begin{array}{l}\text { Loss of CD28 expression characterized by telomere } \\
\text { shortening and reduced proliferative ability }\end{array}$ & $\begin{array}{l}\text { CD28 expression detection in chronic viral infections } \\
\text { and autoimmune disease }\end{array}$ \\
\hline Cancer & $\begin{array}{l}\text { Telomerase deficiency promotes early progression of cancer } \\
\text { by increasing chromosomal instability, telomerase } \\
\text { activation causes tumor cells to unlimitedly proliferate and } \\
\text { cause tumor deterioration }\end{array}$ & $\begin{array}{l}\text { Telomerase inhibitor (imetelstat) effectively inhibits } \\
\text { the incidence of acute myeloid leukemia and } \\
\text { recurrence after chemotherapy }\end{array}$ \\
\hline Coronary heart disease & $\begin{array}{l}\text { Shorter leukocyte telomere length associated with increased } \\
\text { risk of coronary artery disease }\end{array}$ & $\begin{array}{l}\text { Genetic risk scores (GRSs) based on SNPs developed } \\
\text { to predict susceptibility to cardiovascular disease }\end{array}$ \\
\hline Hypercholesterolemia & $\begin{array}{l}\text { Hypercholesterolemia caused a significant reduction of } \\
\text { telomere length }\end{array}$ & $\begin{array}{l}\text { Treatment with antioxidant } \mathrm{N} \text {-acetylcysteine } \\
\text { reversed the oxidant-induced changes }\end{array}$ \\
\hline Type 2 diabetes & $\begin{array}{l}\text { Telomerase activity and telomere length important in } \\
\text { maintaining glucose homeostasis }\end{array}$ & $\begin{array}{l}\text { Injection of liver } X \text { ligands increased telomeric } \\
\text { catalytic subunit expression, improved the } \\
\text { metabolism of triglycerides }\end{array}$ \\
\hline Bone marrow failure & Genetic defects in telomere maintenance and repair & $\begin{array}{l}\text { Danazol (androgens) useful as treatment for marrow } \\
\text { failure syndromes }\end{array}$ \\
\hline
\end{tabular}




\section{Diabetes}

There is a growing body of evidence in support of an association between short telomeres and type 2 diabetes. It is proved that telomerase is important in maintaining glucose homeostasis in mice. [34] Conversely, elevated blood glucose levels increase oxidative stress, potentially interfering with telomerase function and resulting in shortened telomeres. [35] In the Strong Heart Family Study, Zhao et al. investigated the association of leukocyte telomere length at baseline with future risk of diabetes over an average follow-up period of over 5 years. The authors found that individuals in the lowest quartile of leukocyte telomere length were at almost twice the risk of developing diabetes compared with those with longer telomeres. [36] Injection of liver $X$ ligands to high glucose fed rats increased telomeric catalytic subunit expression, inhibited arterial endothelial cell senescence, and improved the metabolism of triglycerides. [37]

\section{Bone Marrow Failure}

Genetic defects in telomere maintenance and repair cause telomere disease, like bone marrow failure, liver cirrhosis, and pulmonary fibrosis. In 2016, Dr. Danielle M. Townsley found that treatment with danazol, androgens, led to telomere elongation in patients with telomere diseases. In bone marrow failure patients, telomere attrition was reduced in all twelve patients who could be evaluated for the primary end point; unexpectedly, almost all the patients (eleven of twelve, 92\%) had a gain in telomere length at 24 months. [38]

Telomere depletion is closely related to cell senescence. Diabetes, coronary heart disease, psychological stress, hormones, and high blood pressures are all risk factors to accelerate telomere shortening.

\section{Cancer and Telomeres}

As previously mentioned, telomere shortening is characteristic of normal cells, and telomerase is the main mechanism regulating telomere elongation. In humans, telomerase activity is known to be only up-regulated in the cells that need to maintain an active proliferative and renewal potential, such as embryonic stem cells and germ-line cells. In contrast, most cancers $(85-90 \%)$ display telomerase activity. [39] Although tumors are likely to occur in cells with short telomeres and chromosomal instability, activation of telomerase activity and telomere maintenance are necessary conditions for most human tumor cells. [40] In 2013, Dr. Horn and Dr.
Huang investigated the correlation of mutations within the core promoter of telomerase reverse transcriptase (TERT), the gene coding for the catalytic subunit of telomerase, with melanoma in mouse and human respectively. [41, 42] Both of them found that these mutations increased transcriptional activity of the TERT promoter by two to four fold and promote the melanoma risk. These studies proved that somatic mutations in regulatory regions of the genome of telomerase may represent an important tumorigenic mechanism. Another study found that late-generation Terc-/-mice, which have short telomeres and are telomerase-deficient, are resistant to tumor development in multi-stage skin carcinogenesis. This result has led to the proposition that telomerase inhibition may result in the cessation of tumor growth. [43]

It is currently known that replicative senescence arises when progressive reduction of telomere length ends up with t-loop collapse and dysfunctional telomeres. [44] Consequently, this dysfunctional telomere becomes an open unprotected state that promotes genome instability, activate DNA damage response, and subsequently result in telomere fusion between distinct chromosomes or sister chromatids. $[45,46]$

Similarly, telomere dysfunction, driven by shelterin modification, can also results in end-to-end chromosome fusions. [47]

Telomere dysfunction leads to DNA-damage signaling and activation of a series of cascade amplification reactions, which activates a series of the tumor-suppressor protein, including p53. P53 can prompt either cellular senescence or apoptosis and plays a critical role in protecting tissues against the tumors. The p53-dependent response to dysfunctional telomeres serves as a strong brake to tumor development in mouse models. [48] A common phenomenon in tumors is the neglect of the protective effect of tumor suppressors, especially in cells lacking p53 or having a mutation in p53. Unchecked telomere shortening drives chromosomal end-to-end fusions and cycles of chromosome fusion-bridgebreakage. The study on incipient cancer cells confirmed that these telomeres must disable p53 signaling to avoid senescence and eventually up-regulate telomerase to achieve cellular immortality. Animal studies where telomeres were rendered dysfunctional following conditional removal or hypomorphic mutations of shelterin proteins in combination with p53 mutations have indicated a high likelihood of tumor genesis. [49, 50] This result proved that circumvention of a telomere-p53 checkpoint is essential for malignant 
progression in human cancer.

In all, these findings demonstrate that telomere uncapping, either through loss of the G-rich overhang itself or by critically shortening the n (TTAGGG) tract of DNA, can trigger, in the setting of p53 deficiency, the genome instability that promotes the development of epithelial cancers. It has been found that telomerase deficiency may promote the early progression of cancer by increasing chromosomal instability. Subsequently, telomerase activation causes tumor cells to unlimitedly proliferate. [51]

There are other mechanisms to regulate telomere length, especially in cancer cells. Alternative lengthening of telomeres (ALT) is a recombination-based mechanism that elongates telomeres in around 15\% of immortalized cell lines and human cancer cells. [52, 53] Although the mechanism and causes of ALT are still not well-known, it is well accepted that this mechanism is based on homologous-recombination dependent exchange and/or homologous-recombination dependent synthesis of telomeric DNA. [54]

Regarding the important role of telomerase in the maintenance of tumor cell growth, telomerase inhibitors have been considered as potential therapies for the treatment of tumors. Dr. Bruedigam found that telomerase inhibitors, which competitively bind telomerase RNA component TERC, can effectively inhibit the incidence of acute myeloid leukemia and recurrence after chemotherapy. [55] Telomerase overexpression represents a potential treatment of age-related diseases. However, this approach takes the risk of causing cancer. So this treatment strategy should be performed carefully to ensure that it does not induce cancer development in patients with a deficiency in tumor suppressor mechanisms.

\section{Aging and Telomeres}

\section{Mechanism of Aging and Telomeres}

In humans, aging is the process of the accumulation of physical and psychological changes over time.

The main mechanism leading to senescence may be progressive DNA damage and progressive shortening of telomere length. [56] In 1973, Dr. Olovnikov first proposed the "telomere theory" of aging and found cellular senescence may be caused by loss of cell renewal ability due to some telomere-related gene mutation. [57] Dr. Harley refined this theory in 1990, arguing that the mechanism of cellular senescence is that highly differentiated somatic telomerase is inhibited and cannot compensate the telomere DNA loss during cell replication; thus, telomere length continues to decrease. [58]

When shortened to the critical limit, the telomeres trigger the signal that terminates cell division and activates the tumor suppressor gene, p53 or $\mathrm{Rb}$ gene, irreversibly preventing cell mitosis. If the cells at this time are transfected by the virus (such as SV40, HPV, etc.) or underwent p53 gene mutation or $\mathrm{Rb}$ gene inactivation, instead, the cells continue to divide and telomere length is further shortened until the DNA is damaged and causes a cell death response. Most of the cells die, with very few cells escaping death by activating telomerase, meaning that a small part of the cells gets "immortalized" into an infinitely proliferating cell. This is also a popular topic in the anti-aging field. [59]

Blackbum discovered that the telomeres have two states, capped and uncapped states. [60] Capped telomeres protect the integrity of the telomeres and maintain normal cell division. Telomeres can be randomly transferred between uncapped to capped. Telomeres with long sequence are easy to be capped; short telomeres are difficult to be capped. It is possible to "immortalize" the cells by activating the telomerase uncapped state. Therefore, Blackbum believed that the length of telomeres plays an important role in determining cell aging.

Aging is also related to the telomerase activity. Dr. Geserick has found that, in mice, telomerase overexpression or low expression leads to premature aging. [61] Dr. Bernardes and Dr. Jaskelioff found that either in pre-old model mice or in normal mice, telomerase activation plays a significant role in anti-aging. [62, 63] These results suggest that the reactivation of telomerase in adult or aged mice can significantly delay aging in mice.

\section{Aging and Telomere Length}

In humans, telomere length gradually shortens as the human body ages. The research on genetically engineered deficiencies in telomerase and other telomere-maintenance proteins have confirmed that short telomeres curtail the lifespan of mice. [64-66] This result suggests that an individual's lifespan has a positive correlation with telomere length; comparatively short telomere length is considered biologically older than its peers. On the other hand, the data from the GERA (over 100,000 individuals) cohort also showed that telomere length was positively correlated with lifespan in subjects over 75 years of age. [67] The research on premature aging disease, Werner syndrome (WS) patients, found that telomere length correlated with senescence, shorter telomere length correlated to more severe 
senescence. [68]

In humans, the rate of telomere length shortening is considerably faster during early stages of growth and development than throughout adulthood. [69, 70] The telomere length of some special cells in the cerebral cortex, neurons, and cardiomyocytes do not change with age. Telomere length of these poorly proliferative tissues remained relatively stable throughout their life cycle. [71]

The rate of telomere shortening differs among species too. Telomere length in human blood cells is shortened by an average of 31-72 base pairs per year, whereas the blood cells of mice are shortened by 100 times faster. [72, 73] This may explain, in part, the difference in life span between the humans and mice. Even different human races show different telomere length. Africans have an average 400 base pairs longer leucocyte telomeres than African Americans, which in turn, is longer by about 200 base pairs than that of individuals of European ancestry. [74]

Therefore, in different species, different race, or even in different tissue of the same individual, the mechanism of telomere shortening may not be same throughout aging process.

\section{Non-genetic Influences on Human Telomere Length}

Telomere shortening is associated with aging, mortality, and aging-related diseases. The telomere length is controlled by not only the end replication problem and telomerase compensation but also by a variety of factors. Many detrimental traits and potentially harmful environmental factors are associated with short telomeres in humans.

Telomeres are highly susceptible to oxidative stress. Oxidative stress-mediated DNA damage is an important determinant of telomere shortening. [75] Oxidative stress most likely acts on thymine and guanine. Free radicals, $\mathrm{O}-2$ o (oxygen ions) and $\mathrm{H} 2 \mathrm{O} 2$ (hydrogen peroxide), may induce DNA damage, which in turn results in the loss of telomere single-stranded fragments and shortening telomere length. The rate of telomere shortening due to free radicals $(100 \mathrm{bp})$ is much faster than what is caused by the end-replication problem (20bp). Antioxidant treatment can reduce telomere damage and alleviate aging. [76]

On the other hand, moderate increase in breast cancer risk among women with shorter telomeres and lower dietary intake of beta carotene, vitamin $C$ or $E$ is also reported in the Long Island Breast Cancer Study Project. [77]

Shortened telomere length has been associated with elevated concentrations of pro-inflammatory cytokines interleukin (IL)-6 and tumor necrosis factor (TNF-a). Dysregulation of inflammation with age is found in almost every living organism. Chronic inflammation is characterized by increased blood levels of several inflammatory biomarkers, including interferon- $\gamma($ IFN - $\gamma)$, interleukin-6 (IL-6), IL-18, and tumor necrosis factor- $\alpha$ (TNF- $\alpha$ ). [78] Shortened telomere length has been associated with elevated concentrations of pro-inflammatory cytokines interleukin (IL)-6 and tumor necrosis factor (TNF-a). [79]

Other factors reported to be associated with telomere length range from social and environmental factors to lifestyle factors. Telomere length has been assessed in human cells in response to aerobic training, resistance training, and self-reported physical action. The result shows low exercise levels of activity associated with shorter telomeres; moderate levels of activity are more commonly associated with longer telomere length. [80, 81]

Lifestyles can also affect telomere length, such as smoking, alcoholism, and obesity. [82-84] An unhealthy diet (such as high cholesterol, high sugar, and high calorie) can accelerate telomere loss through oxidative stress or chronic inflammation. [85] Müezzinler's study found that telomere length and body mass index were negatively correlated and showed a dose-response relationship. [86]

More and more studies show how social stress-induced depression induces abnormal secretion of corticosteroids closely affecting the telomere length. Telomere length is shorter in patients with depression than in healthy individuals, with a biological age of up to about 10 years in patients with severe depression compared with healthy individuals. $[87,88]$

The study on patients with low risk prostate cancer proved the effect of comprehensive lifestyle changes on telomerase activity and telomere length. The telomeres of the patients with positive improvements in lifestyle averaged 10\% longer than the patients in the control group. [89] Balanced diet, moderate aerobic exercise, and a full range of pressure regulation contributed to the reduction of telomere shortening in patients with prostate cancer.

\section{Anti-Aging Therapies with Telomerase}

Telomerase adds telomeric repeats to the ends of chromosomes and is responsible for telomere length maintenance. The expression of telomerase is associated with cell immortalization. This concept has been promoted by the study on the mouse model of telomerase overexpression. In this model, the proportion of mice reaching old age was considerably 
increased, demonstrating an anti-aging activity of telomerase in a mammalian organism. [89] The fact that TERT-transgenic expression in a TERC-deficient background did not affect survival suggests that telomere maintenance is the main mechanism underlying the anti-aging phenomenon of TERT-transgenic mice. [90, 91] Introduction of human telomerase into normal cells induces telomere elongation and life span extension suggesting a pivotal role for telomerase in preventing cellular senescence. [92, 93] Small-molecule activator of telomerase (TA-65) treatment results in telomerase-dependent elongation of short telomeres and rescue of associated DNA damage in haploinsufficient mouse embryonic fibroblasts. [94]

It has been found that natural compounds, such as sex hormones, can bind to the telomerase reverse transcriptase gene promoter region and regulate telomerase reverse transcriptase activity at the transcriptional level. [95] In the mouse model of short-term telomerase-induced aplastic failure, androgen therapy avoided the aging of mice, suggesting that telomerase activation may be a treatment option for diseases associated with telomere deficiency. [96]

The ability of telomerase to maintain normal human cells in a phenotypically youthful state, treat disease associated with telomere deficiency, and extend life span could make it an important target in research and medicine, but overexpressing telomerase promotes cancer cells formation and growth. Failures to arrest growth in response to senescence or transforming growth factor beta (TGF-beta) are key derangements associated with carcinoma progression. Transgenic mice overexpressing telomerase in keratinocytes have an increased chance of carcinogen-induced epidermal tumors. [97]

Therefore, the application of telomerase needs to be further studied.

\section{Conclusion}

Senescence is an extremely complex process. Many different factors constitute a complicated source network, and a single prevention and treatment does not treat all situations. But it is becoming apparent that reversing telomeres length shortening by temporary activating telomerase may be a potent way to slow aging. Telomerase plays a double-edged sword role in aging and cancer. Telomerase overexpression in an aging body can protect the telomeres, prevent telomeres from further shortening, and thereby impair tissue degeneration resulting in an anti-aging effect. It can also lead to cell over-proliferation and the occurrence of tumors.
Senescence of the cell and organs appears as an aging phenomenon, eventually causing irreversible damage and death. However, this has been well applied in the prevention and treatment of tumors.

Can the harmful effects of aging on the body be removed and its beneficial effects be saved for cancer therapy? In the coordination of tumor suppressor proteins, like $\mathrm{p} 53$, if the activation of telomerase is controlled in the effective range, the treatment targeting the telomere function and telomerase activity may effectively control tumors and prevent aging. [98] This can be a new way to treat age-related diseases and successfully control tumor genesis.

\section{Competing Interests}

The authors have declared that no competing interest exists.

\section{References}

1. Martin M. The biology of aging: $1985-2010$ and beyond. FASEB journal: official publication of the Federation of American Societies for Experimental Biology. 2011,25 (11): 3756-3762.

2. Hayflick L, Moorhead PS. The serial cultivation of human diploid cell strains. Exp Cell Res. 1961, 25 (3): 585-621.

3. Bodnar AG, Ouellette M, Frolkis M, Holt GE, Chiu C, Morin GB, Harley $\mathrm{CB}$, Shay JW, Lichtsteiner S, EWright W. Extension of life span by introduction of telomerase into normal human cells. Science. 1998, 279:349-352.

4. Vaziri H, Benchimol S. Reconstitution of telomerase activity in normal human cells leads to elongation of telomeres and extended replicative life span. Curr Biol. 1998, 8: 279-282

5. Blasco MA. Telomere length, stem cells and aging. Nat. Chem. Biol. 2007, 3: 640-649.

6. Donate LE, Blasco MA. Telomeres in cancer and ageing. Phil. Trans. R. Soc.B. 2011, 366: 76-84.

7. Cheong $\mathrm{C}$, Hong KU, Lee HW. Mouse models for telomere and telomerase biology. Exp. Mol. Med. 2003, 35: 141-153.

8. Rodriguez-Brenes IA, Peskin CS. Quantitative theory of telomere length regulation and cellular senescence. Proc Natl Acad Sci USA. 2010,107(12):5387-5392.

9. Kim NW, Piatyszek MA, Prowse KR, Harley CB, West MD, Ho PL, et al. Specific association of human telomerase activity with immortal cells and cancer. Science. 1994, 266: 2011-5.

10. Forsyth NR, Wright WE, Shay JW. Telomerase and differentiation in multicellular organisms: Turn it off, turn it on, and turn it off again. Differentiation. 2002, 69:188-197.

11. Asai A, Oshima $Y$, Yamamoto $Y$, Uochi $T$, Kusaka H, Akinaga $S$, Yamashita $Y$, Pongracz K, Pruzan R, Wunder E, et al. A novel telomerase template antagonist (GRN163) as a potential anticancer agent. Cancer Res. 2003, 63: 3931-3939.

12. Joseph I, Tressler R, Bassett E, Harley C, Buseman CM, Pattamatta P, Wright W.E, Shay J.W, Go N.F. The telomerase inhibitor Imetelstat depletes cancer stem cells in breast and pancreatic cancer cell lines. Cancer Res. 2010, 70: 9494-9505

13. Meyne J, Ratliff RL, Moyzis RK. Conservation of the human telomere sequence (TTAGGG)n among vertebrates. Proceedings of the National Academy of Sciences of the United States of America. 1989, 86(18): 7049-7053.

14. McClintock B. The stability of broken ends of chromosomes in Zea mays. Genetics. 1941, 26: 234-282.

15. Müller HJ. The remaking of chromosomes. Collect. Net-Woods Hole 1938, 13: 181-198.

16. Makarov VL, Hirose Y, Langmore JP. Long G tails at both ends of human chromosomes suggest a $\mathrm{C}$ strand degradation mechanism for telomere shortening. Cell. 1997, 88:657-666.

17. Wright WE, Tesmer VM, Huffman KE, Levene S.D, Shay J.W. Normal human chromosomes have long G-rich telomeric overhangs at one end. Genes Dev. 1997, 11: 2801-2809.

18. Griffith J.D, Comeau L, Rosenfield S, Stansel R.M, Bianchi A, Moss H, De Lange T. Mammalian telomeres end in a large duplex loop. Cell. 1999, 97:503-514.

19. Palm W, de Lange T. How shelterin protects mammalian telomeres. Annu Rev Genet. 2008, 42:301-334.

20. de Lange T. How telomeres solve the end-protection problem. Science. 2009, 326(5955): 948-952. 
21. Venteicher AS, Abreu EB, Meng Z, McCann KE, Terns RM, Veenstra TD, et al. A human telomerase holoenzyme: a human telomerase holoenzyme protein required for Cajal body localization and telomere synthesis. Science. 2009, 323 (5914):644-648

22. Blackburn H, Epel S, Lin Jue. Human telomere biology: A contributory and interactive facor in aging, disease resks, and protection. Science. 2015, 350(6265): 1193-1198

23. Vulliamy TJ, Marrone A, Knight SW, Walne A, Mason PJ, Dokal I. Mutations in dyskeratosis congenita: their impact on telomere length and the diversity of clinical presentation. Blood. 2006, 15(7): 2680-2685.

24. Mitchell JR, Wood E, Collins K. A telomerase component is defective in the human disease dyskeratosis congenital. Nature. 1999,15 (6761):551-555.

25. Vulliamy T, Marrone A, Goldman F, Dearlove A, Bessler M, Mason PJ, et al. The RNA component of telomerase is mutated in autosomal dominant dyskeratosis congenital. Nature. 2001,15 (6854) (2001):432-435.

26. Walne AJ, Vulliamy T, Marrone A, Beswick R, Kirwan M, Masunari Y, et al. Genetic heterogeneity in autosomal recessive dyskeratosis congenita with one subtype due to mutations in the telomerase-associated protein NOP10. Hum. Mol. Genet. 2007, 15(13):1619-1629.

27. Lin J, Epel E, Blackburn E. Telomeres and lifestyle factors: roles in cellular aging. Mutation research. 2012 730(1/2): 85-89.

28. Blasco MA. Telomere length, stem cells and aging. Nature Chemical Biology. 2007, 3(10): 640-649.

29. Parish ST, Wu JE, Effros RB. Sustained CD28 expression delays multiple features of replicative senescence in human CD8 T lymphocytes. Journal of Clinical Immunology. 2010, 30(6):798-805.

30. BlascEffros RB, Dagarag M, Valenzuela HF. In vitro senescence of immune cells. Experimental Gerontology. 2003,38(11-12):1243-1249.

31. Scheller MA, Rode L, Nordestgaard BG, Bojesen SE. Short telomere length and ischemic heart disease: observational and genetic studies in 290022 individuals. Clin Chem. 2016, 62: 1140-1149.

32. Codd V, Nelson CP, Albrecht E, et al. Identification of seven loci affecting mean telomere length and their association with disease. Nat Genet, 2013, 45:422-427.

33. Tie G, Messina KE, Yan J, et al. Hypercholesterolemia induces oxidant stress that accelerates the ageing of hematopoietic stem cells. J Am Heart Assoc. 2014, 3: e000241.

34. kuhlow D, Florian $S$, von Figura G, et al. Telomerase deficiency impairs glucose metabolism and insulin secretion. Aging. 2010, 2: 650-658.

35. Serra V, Grune T, Sitte N, Saretzki G, von Zglinicki T. Telomere length as a marker of oxidative stress in primary human fibroblast cultures. Ann N Y Acad Sci. 2000,908:327-330.

36. Zhao J, Zhu Y, Lin J, et al. Short leukocyte telomere length predicts risk of diabetes in American Indians: the Strong Heart Family Study. Diabetes. 2013,63:354-362.

37. Hayashi T, Kotani H, Yamaguchi T, et al. Endothelial cellular senescence is inhibited by liver $x$ receptor activation with an additional mechanism for its atheroprotection in diabetes. Proc Nat Acad Sci, 2014, 111: 1168-1173.

38. Townsley DM, Dumitriu B, Liu D, Biancotto A, Weinstein B, Chen C, Hardy N, Mihalek AD, Lingala S, Kim YJ, et al. Danazol treatment for telomere diseases. N. Engl. J. Med. 2016, 374:1922-1931.

39. Kim NW, Piatyszek MA, Prowse KR, Harley CB, West D, Ho PLC, Coviello GM, Wright WE, Weinrich SL, Shay W, et al. Specific Association of Human Telomerase Activity with Immortal Cells and Cancer. Science. 1994, 266: 2011-2015.

40. Lee M, Lee JS. Exploiting tumor cell senescence in anticancer therapy. BMB Rep. 2014, 47: 51-59.

41. Horn S, Figl A, Rachakonda PS, et al. TERT promoter mutations in familial and sporadic melanoma. Science. 2013, 339: 959-961.

42. Huang FW, Hodis E, Xu MJ, et al. Highly recurrent TERT promoter mutations in human melanoma. Science. 2013, 339: 957-959

43. Gonzalez-Suarez E, Samper E, Flores JM, et al. Telomerase-deficient mice with short telomeres are resistant to skin tumorigenesis. Nat Genet, 2000, 26: 114-117.

44. Karlseder J, Smogorzewska A, de Lange T. Senescence induced by altered telomere state, not telomere loss. Science. 2002,295: 2446-2449.

45. Soler D, Genescà A, Arnedo G, Egozcue J, Tusell L. Telomere dysfunction drives chromosomal instability in human mammary epithelial cells. Genes. Chromosomes Cancer. 2005, 44: 339-350.

46. Deng W, Tsao SW, Guan XY, Lucas JN., Cheung ALM. Role of short telomeres in inducing preferential chromosomal aberrations in human ovarian surface epithelial cells: A combined telomere quantitative fluorescence in situ hybridization and whole-chromosome painting study. Genes Chromosom. Cancer. 2003; 37:92-97.

47. Van Steensel B, Smogorzewska A, de Lange T. TRF2 protects human telomeres from end-to-end fusions. Cell. 1998, 92: 401-413.

48. Feldser DM, Greider CW. Short telomeres limit tumor progression in vivo by inducing senescence. Cancer Cell. 2007,11: 461-469.

49. Martínez P, Thanasoula M, Muñoz P, Liao C, Tejera A, McNees C, Flores JM, Fernández-Capetillo $\mathrm{O}$, Tarsounas M, Blasco MA. Increased telomere fragility and fusions resulting from TRF1 deficiency lead to degenerative pathologies and increased cancer in mice. Genes Dev. 2009, 23: 2060-2075.
50. Pinzaru AM, Hom RA, Beal A, Phillips AF, Ni E, Cardozo T, Nair N, Choi J, Wuttke DS, Sfeir A, et al. Telomere replication stress induced by POT1 inactivation accelerates tumorigenesis. Cell Rep. 2016, 15: 2170-2184.

51. Ding $\mathrm{Z}, \mathrm{Wu} \mathrm{CJ}$, Jaskelioff $\mathrm{M}$, et al. Telomerase reactivation following telomere dysfunction yields murine prostate tumors with bone metastases. Cell. 2012, 148: 896-907

52. Cesare, AJ, Reddel, RR. Alternative lengthening of telomeres: Models, mechanisms and implications. Nat. Rev. Genet. 2010, 11: 319-330.

53. Draskovic I, Londono Vallejo A. Telomere recombination and alternative telomere lengthening mechanisms. Front. Biosci. 2013, 18: 1-20.

54. Londono-Vallejo, JA, Der-Sarkissian, H, Cazes, L, Bacchetti, S, Reddel RR. Alternative lengthening of telomeres is characterized by high rates of telomeric exchange. Cancer Res. 2004, 64: 2324-2327.

55. Bruedigam C, Bagger FO, Heidel FH, et al. Telomerase inhibition efficiently targeted mice and human AML stem cells and delays relapse following chemotherapy. Cell Stem Cell, 2014. 15: 775-790.

56. Shay W. Role of telomeres and telomerase in aging and cancer. Cancer Discovery. 2016, 6(6): 584-593.

57. Olovnikov AM. A theory of marginotomy. The incomplete copying of template margin in enzymic synthesis of polynucleotides and biological significance of the phenomenon. J Theor Biol. 1973, 14,41(1):181-90.

58. Harley CB. Telomere loss: mitotic clock or genetic time bomb? Mutat Res. 1991, 256(2-6):271-82

59. Mather A, Jorm F, Parslow A,et al. Is telomere length a biomarker of aging? A review. The journals of gerontology. Series A, Biological sciences and medical sciences. 2011, 66 (2): 202-213.

60. Blackburn H, Chan S, Chang J, et al. Molecular manifestations and molecular determinants of telomere capping. Cold Spring Harbor symposia on quantitative biology. 2000, 65: 253-263.

61. Geserick CM, Blasco A. Novel roles for telomerase in aging. Mech Ageing Dev. 2006, 127(6):579-583

62. Bernardes de Jesus B, Vera E, Schneeberger K, et al. Telomerase gene therapy in adult and old mice delays aging and increases longevity without increasing cancer. EMBO Mol Med. 2012, 4: 691-704.

63. Jaskelioff M, Muller FL, Paik JH, et al. Telomerase reactivation reverses tissue degeneration in aged telomerase-deficient mice. Nature. 2011, 469: 102-106.

64. Blasco MA. Telomere length, stem cells and aging. Nat. Chem. Biol. 2007, 3: 640-649.

65. Donate LE, Blasco MA. Telomeres in cancer and ageing. Phil. Trans. R. Soc. B. 2011,366: 76-84.

66. Cheong $\mathrm{C}$, Hong KU, Lee HW. Mouse models for telomere and telomerase biology. Exp. Mol. Med. 2003, 35:141-153.

67. Lapham K, Kvale N, Lin J, et al. Automated assay of telomere length measurement and informatics for 100,000 subjects in the genetic epidemiology research on adult health and aging (GERA) cohort. Genetics. 2015, 200(4):1061-1072

68. Reddy S, Li B, Comai L. Processing of human telomeres by the Werner syndrome protein. Cell cycle. 2010, 9 (16): 3137-3138.

69. Aubert G, Baerlocher GM, Vulto I, Poon SS, Lansdorp PM. Collapse of telomere homeostasis in hematopoietic cells caused by heterozygous mutations in telomerase genes. PLoS Genet. 2012, 8: e1002696.

70. Aubert G, Lansdorp PM. Telomeres and aging. Physiol. Rev. 2008, 88:557-579.

71. Nakamura K, Takubo K, Izumiyama-Shimomura N, et al. Telomeric. DNA length in cerebral gray and white matter is associated with longevity in individuals aged 70 years or older. Experimental Gerontology. 2007, 42(10): 944-950.

72. Canela A, Klatt P, Blasco A. Telomere length analysis. Methods in molecular biology. 2007, 371: 45-72.

73. Vera E, Bernardes De Jesus B, Foronda M, et al. The rate of increase of short telomeres predicts longevity in mammals. Cell reports. 2012, 2 (4): 732-737.

74. Hansen ME et al. Shorter telomere length in Europeans than in Africans due to polygenetic adaptation. Hum. Mol. Genet. 2006, 25:2324-2330.

75. Richter T, von Zglinicki T. A continuous correlation between oxidative stress and telomere shortening in fibroblasts. Exp Gerontol. 2007, 42 (11): 1039-42.

76. Ludlow $\mathrm{T}$, Spangenburg $\mathrm{E}$, Chin $\mathrm{R}$, et al. Telomeres shorten in response to oxidative stress in mouse skeletal muscle fibers.The journals of gerontology. Series A, Biological sciences and medical sciences. 2014, 69(7): 821-830.

77. Shen J, Gammon MD, Terry MB, Wang Q, Bradshaw P, Teitelbaum SL Neugut AI, Santella RM. Telomere length, oxidative damage, antioxidants and breast cancer risk. Int Cancer. 2009 (4), 124 (7): 1637-43.

78. Scheller J, Chalaris A, Schmidt-Arras D, Rose-John S. The pro- and anti-inflammatory properties of the cytokine interleukin-6 Biochim. Biophys. Acta. 2011, 1813: 878-888

79. Zhang J, Rane G, Dai X, et al. Ageing and the telomere connection: An intimate relationship with inflammation. Ageing Research. 2016, 25: 55-69.

80. Ludlow AT, Zimmerman JB, Witkowski S, Hearn JW, Hatfield BD, Roth SM. Relationship between physical activity level, telomere length and telomerase activity. Med. Sci. Sports Exerc. 2008, 40:1764-1771.

81. Kim JH, Ko JH, Lee DC, Lim I, Bang H. Habitual physical exercise has beneficial effects on telomere length in postmenopausal women. Menopause. 2012, 19:1109-1115. 
82. Verde Z, Reinoso-Barbero L, Chicharro L, et al. Effects of cigarette smoking and nicotine metabolite ratio on leukocyte telomere length. Environmental Research. 2015, 140: 488-494.

83. Strandberg E, Strandberg Y, Saijonmaa Outi, et al. Association between alcohol consumption in healthy midlife and telomere length in older men. The Helsinki Businessmen Study. European Journal of Epidemiology. 2012,27(10): 815-822.

84. Chen SF, Yeh F, Lin J, et al. Short leukocyte telomere length is associated with obesity in American Indians: The Strong Heart Family study. Aging. 2014, 6(5): 380-389.

85. Freitas-Simoes M, Ros E, Sala-Vila A. Nutrients, foods, dietary patterns and telomere length: Update of epidemiological studies and randomized trials. Metabolism Clinical and Experimental. 2016, 65(4): 406-415.

86. Müezzinler A, Mons U, Dieffenbach K, et al. Body mass index and leukocyte telomere length dynamics among older adults: Results from the ESTHER cohort. Experimental Gerontology. 2016, 74:1-8.

87. Ridout $\mathrm{K}$, Ridout J, Price $\mathrm{H}$, et al. Depression and telomere length: A meta-analysis. Journal of Affective Disorders. 2016, 191: 237-247.

88. Simon M, Smoller W, Mcnamara L, et al. Telomere shortening and mood disorders: preliminary support for a chronic stress model of accelerated aging. Biological Psychiatry. 2006, 60(5):432-435.

89. Ornish D, lin J, Chan JM, et al. Effect of comprehensive lifestyle changes on telomerase activity and telomere length in men with biopsy proven low risk prostate cancer: 5 year follow-up of a descriptive pilot study. The Lancet Oncology. 2013, 14(11): 1012-1120.

90. Martínez P, Blasco MA. Telomeric and extra-telomeric roles for telomerase and the telomere- binding proteins. Nat Rev Cancer. 2011, 11: 161-176.
91. Tomás-Loba A, Flores I, Fernández-Marcos PJ, Cayuela ML, Maraver A, Tejera A, Borrás C, Matheu A, Klatt P, Flores JM, Viña J, Serrano M, Blasco MA. Telomerase reverse transcriptase delays aging in cancer-resistant mice. Cell. 2008, 135: 609-622.

92. Bodnar AG, Ouellette M, Frolkis M, Holt SE, Chiu CP, Morin GB, Harley CB, Shay JW, Lichtsteiner S, Wright WE. Extension of life-span by introduction of telomerase into normal human cells. Science. 1998, 279: 349-352.

93. Vaziri H, Benchimol S. Reconstitution of telomerase activity in normal human cells leads to elongation of telomeres and extended replicative life span. Curr Biol. 1998, 8: 279-282.

94. Bernardes De Jesus Bruno, Schneeberger Kerstin,Vera Elsa, et al. The telomerase activator TA-65 elongates short telomeres an dincreases health span of adult / old mice without increasing cancer incidence. Aging Cell. 2011, 10(4): 604-621.

95. Calado T, Yewdell T, Wilkerson L, et al. Sex hormones, acting on the TERT gene, increase telomerase activity in human primary hematopoietic cells. Blood. 2009, 114(11): 2236-2243.

96. Jaime-Pérez C,Colunga -Pedraza R, Gómez-Ramírez D, et al. Danazol as first-line therapy for aplastic anemia. Annals of Hematology. 2011, 90(5): 523-527.

97. González-Suárez E, Samper E, Ramírez A, Flores JM, Martín-Caballero J, Jorcano JL, Blasco MA. Increased epidermal tumors and increased skin wound healing in transgenic mice overexpressing the catalytic subunit of telomerase, mTERT, in basal keratinocytes. EMBO J 2001, 20: 2619-2630.

98. Hartwig FP, Bertoldi D, Larangeira M, et al. Up-regulat-ing telomerase and tumor suppressors: focusing on anti-aging interventions at the population level. Aging Dis. 2014, 5: 17-26. 